\title{
Loss Estimation of Steel Buildings to Earthquake Mainshock-Aftershock Sequences
}

\author{
${ }^{1}$ Ruiqiang Song, ${ }^{2}$ Yue Li, and ${ }^{3}$ John W. Van de Lindt
}

\begin{abstract}
Following a large earthquake numerous aftershocks can be triggered due to the complex stress interaction between and within tectonic plates. Although aftershocks are normally smaller in magnitude, their ground motion intensity can be large and have different energy content than the mainshock. Even seemingly undamaged buildings may be damaged as a result of aftershocks. The mainshock-damaged buildings with deteriorated structural properties are more susceptible to damage.

This paper proposes a framework for loss estimation of steel structures subjected to mainshockaftershock sequences. The analysis is based on a typical 4-story steel frame with a deterioration model. Mainshocks are modeled as a homogeneous Poisson process, while aftershocks are simulated from non-homogeneous Poisson process, magnitudes of which are characterized by the Gutenberg-Richter relationship. The proposed framework is applied to examine the effects of aftershocks on seismic loss. The expected seismic loss of the building subjected to two levels of earthquakes, the Design Earthquake (DE) and the Maximum Considered Earthquake (MCE), followed by aftershocks are examined considering both transition cost and downtime cost. Monte Carlo Simulation (MCS) with Latin Hypercube Sampling (LHS) is applied to examine the uncertainty in the loss estimation. Uncertainty in earthquake ground motions, structural model, damage and loss are all considered. It was found that even if aftershocks have little effect on structural response, they may still have a significant impact on seismic loss due to the uncertainty of the damage state and cost estimation. This methodology can be used to mitigate seismic loss and evaluate the current building design.
\end{abstract}

Keywords: Aftershock hazard, Collapse, Degraded system, Fragility, Performance-Based Engineering, Steel structures, Loss estimation, Monte Carlo Simulation, Uncertainty

${ }^{1}$ Formerly Graduate Research Assistant, Department of Civil and Environmental Engineering, Michigan Technological University, Houghton, Michigan, USA.

${ }^{2}$ Associate Professor, Department of Civil Engineering, Case Western Reserve University, Cleveland, Ohio, USA, E-mail: yue.li10@case.edu

${ }^{3}$ George T. Abell Professor in Infrastructure, Department of Civil and Environmental Engineering, Colorado State University, Fort Collins, Colorado, 80523-1372; USA 


\section{Introduction}

A large mainshock can trigger numerous aftershocks because of the complex stress interaction between and within tectonic plates [1]. Aftershocks have the potential to cause severe damage to mainshock-damaged buildings, threaten life safety, and result in significant economic losses even when only minor damage is present from the mainshock. The 2012 East Azerbaijan earthquake hit northeast of Tabriz on August 11, 2012, and the strongest aftershock measured at M6.3 occurred eleven minutes after the M6.4 mainshock. The mainshock-aftershock sequence caused at least 327 deaths and more than 3000 other injuries [2]. On April 11, 2012, a M8.6 earthquake struck Indonesia, followed by several strong aftershocks with the largest measured at M8.2 just over two hours later, according to the United States Geological Survey [3]. The great Tohoku earthquake on March 11, 2011 in Japan, triggered 60 aftershocks with magnitude 6.0 or greater and three over magnitude 7.0. The total economic loss in Japan was estimated at \$309 billion [4]. The February 2011 M6.3 Christchurch earthquake was triggered by the 2010 M7.1 Canterbury earthquake. It incurred approximately $\$ 15$ billion of rebuilding costs and 181 people were killed [5]. The M8.8 Chile earthquake on February 27, 2010 incurred 304 aftershocks of magnitude 5.0 or greater in the following two months [6] and the earthquake's losses were estimated about $\$ 30$ billion [7]. Therefore, the effect of mainshock-aftershock (MS-AS) sequences, rather than just the mainshock alone, should be taken into account to evaluate the seismic performance of buildings.

The magnitudes of aftershocks are usually less than the mainshock, but an aftershock record may have a higher peak ground acceleration (PGA), longer duration, larger intensity, and different energy content than the mainshock [8]. Figure 1 presents an example of an earthquake mainshock-aftershock sequence [9]. The aftershocks have the potential to result in a larger seismic demand for a specified building, e.g. large spectral acceleration at the fundamental period of the building. Buildings with deteriorated structural properties are even more susceptible to damage from aftershocks. Occurrence of space and time-dependent aftershocks can be characterized by a non-stationary stochastic process. In general, the occurrence rate of aftershocks decreases with time after the mainshock. The delay between the mainshock and largest aftershock can range between several minutes to months. It is not realistic that the building damaged by the mainshock is repaired to an intact state immediately or before the next aftershock. It can take two years or longer to reopen mainshock-damaged buildings depending on the damage level and the aftershock intensities [10], which can result in significant financial loss from business downtime, in addition to human fatalities and repair cost. 


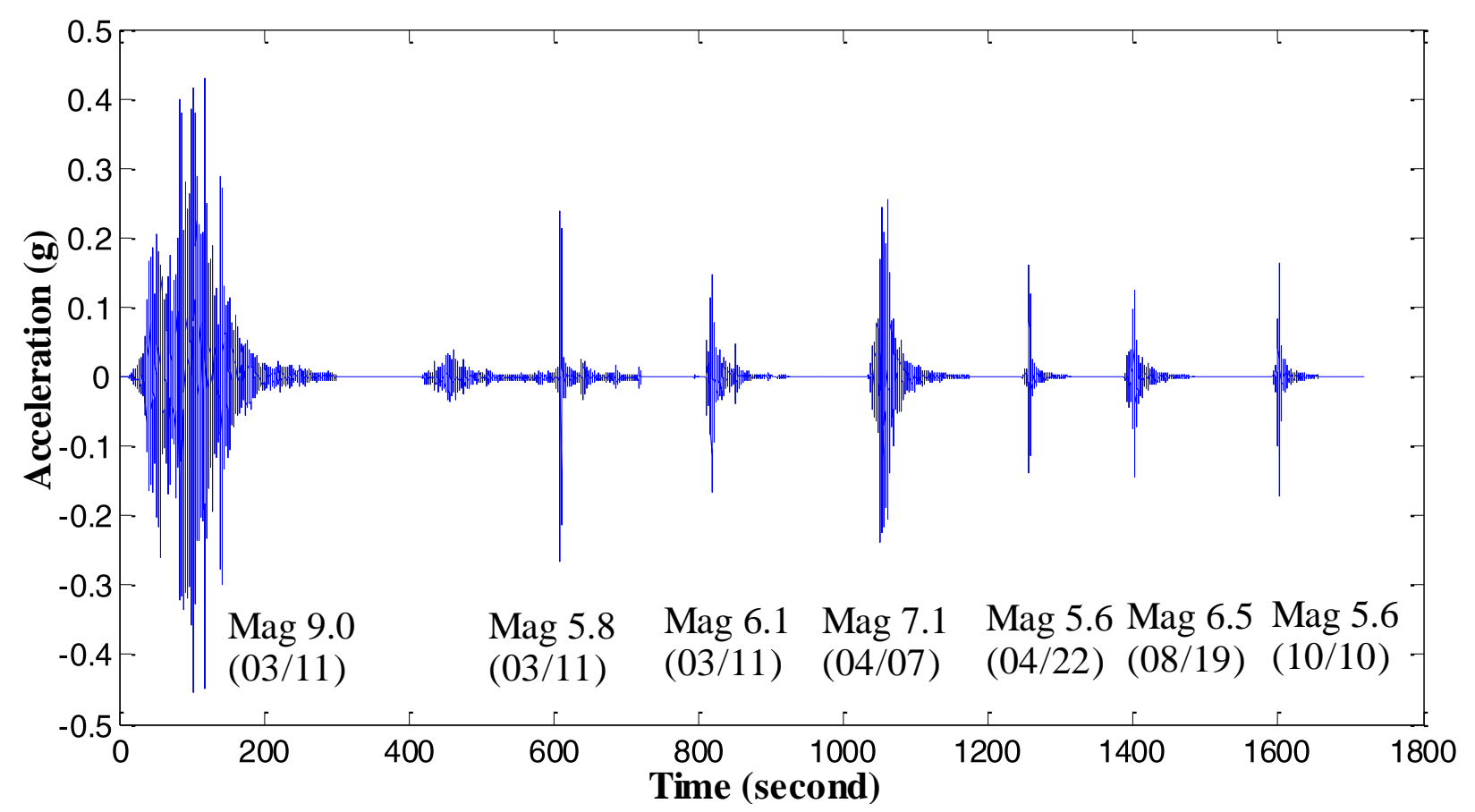

Figure 1. An example of seismic sequence recorded at Haramachi station from 2011 Tohoku earthquake, Japan

The premise of current building codes is based on minimum life-safety design and does not provide provisions to mitigate the risk of seismic loss in earthquake events [11]. However, recent earthquakes have demonstrated that when moderate or severe earthquakes occur, the buildings designed under modern US building codes may suffer significant economic loss although human life has been adequately protected [11, 12] which is the intent of the design codes. The magnitude of earthquake economic loss suggests it is necessary to consider other aspects of structural seismic performance besides the minimum life-safety design in modern building codes. Earthquake loss has been considered by researchers in the seismic design community since the early 1970s (e.g. [13]). The Pacific Earthquake Engineering Research (PEER) Center has proposed a conceptual framework for performance-based earthquake engineering (PBEE), which can be used to evaluate several components of total seismic loss, including economic loss, downtime, and casualties [14]. One topic of current research in PBEE is the determination of loss estimation and the uncertainty of the estimation [15]. In order to facilitate a framework in practice, the Applied Technology Council [16] formalized the performance-based seismic design process by examining three types of performance assessment: intensity-based, scenario-based and time-based. Based on the quantitative measures of structural performance, the risk of the probable seismic loss and its influence on structural design decision-making can be evaluated in PBEE. HAZUS-MH [17] has established a methodology for regional seismic loss estimation by calculating structural response, damage, and repair costs using generic building capacity and fragility functions. The Advanced Engineering Building Module (AEBM), which was recently 
enhanced in HAZUS-MH [18] permits users to capture building-specific damage and loss estimation.

Many researchers have recently looked into seismic loss estimation for different structural types. Porter and Kiremidjian [19] developed an assembly-based vulnerability (ABV) framework for probabilistic financial loss evaluation by calculating the summation of assembly level component losses. Goulet et al. [20] applied the PEER methodology to predict the seismic performance, termed financial loss and collapse safety, of a reinforced concrete moment-frame building, and the relevant sensitivity was investigated. Haselton et al. [21] assessed the performance of a fourstory reinforced concrete office building and the performance was quantified in terms of collapse safety, financial losses and fatalities, and different building configurations were taken into account. Mitrani-Reiser [22] implemented the PEER's loss assessment methodology using a MATLAB Damage and Loss Analysis (MDLA) toolbox to estimate the economic losses of a reinforced-concrete moment-frame building. The uncertainty propagation for the PEER seismic loss estimation framework was examined by Baker and Cornell [15] using the first-order secondmoment (FOSM) method. Ramirez and Miranda [23] developed a story-based loss estimation approach to simplify PEER's framework by relating structural response directly to loss for each story. Yeo and Cornell [10] proposed stochastic financial loss estimation models over the structural lifetime due to mainshocks and their aftershocks sequences, and a more general Markov and semi-Markov framework for modeling mainshock occurrence with various building damage states was also developed. Pei and van de Lindt [24] proposed a probabilistic framework to assess the long-term seismic financial loss of woodframe structures using a Bayesian model which allowed one to incorporate subjective engineering experience and test data. Bradley and Lee [25] investigated the efficacy of the FOSM method of uncertainty propagation and concluded that great care should be taken, particularly considering the large uncertainties that must be propagated because of large error in the results. Yin and Li [26] proposed an objectoriented framework to estimate seismic losses to light-frame wood buildings to mainshockaftershock sequences, and showed that the aftershocks and downtime cost are important contributors to total seismic loss. Sanchez-Silva et al. [27] investigated the structural life-cycle performance accounting for loss of sudden events (e.g. seismic loss) and progressive degradation, and found that the progressive deterioration has a significant impact on the structural failure. Ramirez et al. [11] examined the expected repair cost in a set of 30 archetype reinforced concrete moment frame buildings and the result showed the repair cost varies significantly depending on building height and other structural parameters.

Most of the current approaches are based on the assumption that the building damage sustained from an earthquake can be repaired to their intact state immediately and therefore aftershocks were not taken into account, even though it may have a significant influence on the earthquake loss estimation. Some recent research investigating the effects of earthquake aftershocks on buildings and other infrastructure includes Nazari et al. [28] and others [8, 29-35], but loss 
estimation of steel buildings subjected to aftershock hazard has not been examined. In this study, a framework for loss estimation of steel structures subjected to mainshock-aftershock sequences is proposed, which consists of four components: hazard analysis, structural analysis, damage analysis and loss analysis. The framework is demonstrated using a four-story steel frame with a deterioration model calibrated using existing experimental data in NEEShub [36, 37]. Mainshocks are modeled as a homogeneous Poisson process, while aftershocks are simulated from non-homogeneous Poisson process, magnitudes of which are characterized by the Gutenberg-Richter relationship. The maximum interstory drift obtained in the nonlinear dynamic analysis is employed as the engineering demand parameter to determine the damage state. The expected seismic losses of the building subjected to two levels of earthquakes including, Design Earthquake (DE) and Maximum Considered Earthquake (MCE) and their following aftershocks, are examined considering both transition cost and downtime cost. The transition cost includes the structural and nonstructural damage costs, as well as the costs of evacuation of the occupants following an earthquake event, and downtime cost is the financial loss due to the building's closed operation or limited functionality [10]. Monte Carlo Simulation (MCS) is applied to examine the uncertainty of loss estimation, and the Latin Hypercube Sampling (LHS) technique is used to reduce the computational demand and improve the accuracy of the loss estimation. This research is part of broader effort to ultimately consider mainshock-aftershock sequences in PBEE. It can contribute to the improvement of current building-specific loss estimation methodologies and help stakeholders make better design decisions when aftershock hazard is considered.

\section{Framework of Loss Assessment Considering Mainshock-Aftershock Sequences}

The conceptual framework for seismic loss estimation proposed by the PEER center consists of four components: site-specific seismic hazard, structural response, damage to building components and contents, and seismic loss analysis. Based on the PEER framework, several computational procedures have recently been proposed [11, 16, 24, 26]. An approach in Pei and van de Lindt [24], ATC-58 [16] and Ramirez et al. [11] was termed a fragility-based framework in which the fragility curves are essential components of each respective analysis. In the fragility-based framework, the interval time, number and intensity of aftershock sequences have not been explicitly examined which may significantly underestimate the seismic risk [26]. Yin and $\mathrm{Li}$ [26] proposed an objected-oriented framework to take into account the aftershock effects in seismic loss estimation.

The framework for loss assessment applied in this study is shown in Figure 2. The framework consists of four objects corresponding to the four components of the PEER framework, i.e., hazard analysis, structural analysis, damage analysis and loss analysis. Each object in the framework has an interface to exchange data with external procedures and the built-in numerical models in the objects can be updated and executed independently. The propagation of uncertainties is explicitly considered in the framework. 


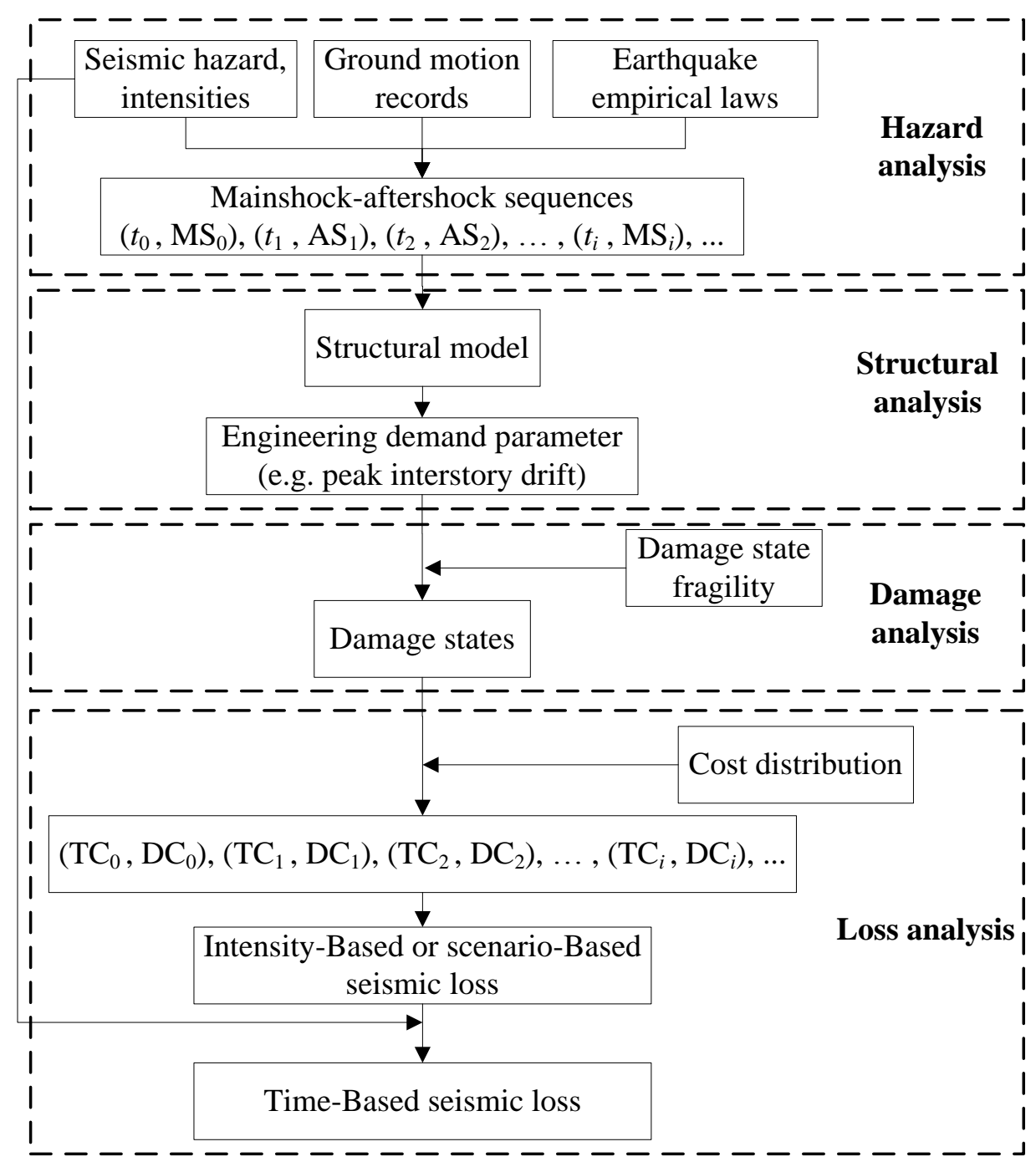

Figure 2. Framework for seismic loss estimation

The hazard analysis objective is to determine the mean annual rate of exceedance of ground motion at a specific site, taking into account the type of nearby faults, the distance to the site, and other factors [30]. The mainshock-aftershock sequences are simulated in the object. The structural analysis object contains a structural analytical model. After inputting the simulated mainshock-aftershock sequences, the nonlinear dynamic analysis is carried out based on the structural model to obtain the structural engineering demand parameter. Then the structural responses are convolved with the damage state fragility curves to determine damage states corresponding to the input shocks in the damage analysis object. Finally, the seismic loss is calculated by relating the structural damage states to the cost distribution. More details are discussed in the section on Seismic Loss Assessment. 


\section{Calibrated Structural Model for Steel Building}

The framework is applied to calculate the earthquake-induced financial loss for a modern codeconforming four-story steel moment-resisting frame building [28]. The structural lateral force resisting system consists of steel special moment-resisting perimeter frames with the fully restrained reduced beam sections (RBS). The design is in accordance with the 2003 International Building Code [31], the 2002 Minimum Design Loads for Buildings and Other Structures [40], and the 2005 American Institute of Steel Construction seismic provisions [33]. The prototype four-story steel moment-resisting frame structure in the East-West (EW) direction (shown in Figure 3) is selected as the focus of the study. The first three modal periods of the EW frames are $1.33,0.43$, and $0.22 \mathrm{~s}$, respectively. In order to verify the accuracy of analytically predicted sidesway collapse of the frame structure, Lignos et al [36,37] tested two 1:8 scale model frames to collapse on the shaking table at NEES facility at the State University of New York at Buffalo. Full details of the model and tests can be found in Lignos et al. [36, 37]. The testing data can be accessed at the NEES data repository in NEEShub.

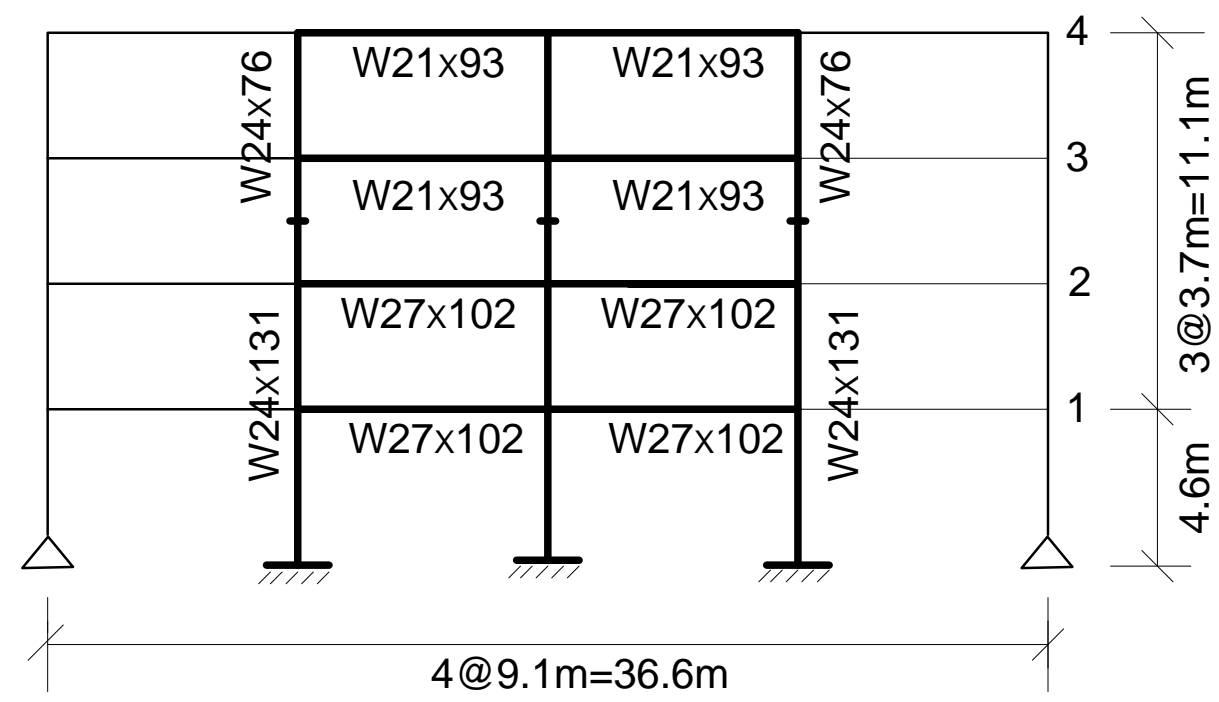

Figure 3. Four-story steel building in EW direction

The analytical model of the steel moment-resisting frame in EW direction was developed using the Open System for Earthquake Engineering Simulation platform [42]. The frame was simulated by concentrated plasticity model, which consists of elastic beam-column elements connected by zero length elements served as the plastic hinge rotational spring [37,43]. The structural nonlinear behavior is represented by the plastic hinge rotational spring based on the Modified Ibarra-Krawinkler Deterioration Model shown in Figure 4 [36]. The model utilizes a multilinear backbone curve that defines a boundary for structural behavior and cyclic hysteretic model taking into account both strength and stiffness deterioration. The deterioration models including basic strength, post-capping strength, and unloading stiffness deterioration, are 
accounted in the multilinear hysteretic model, as illustrated in Figure 4. The cyclic deterioration rate is based on the reference hysteretic energy dissipation capacity of the structural component defined as $E_{t}=\Lambda \cdot M_{y}$, where $\Lambda$ is the reference cumulative rotation capacity which is a component property, and $M_{y}$ is the effective yield strength of the component [44]. The parameters in the model of structural steel components were determined and calibrated from more than 300 steel specimens [44].

P-Delta effects were taken into account by linking a leaning column that carries gravity loads to the frame, which is modeled as beam-column elements jointed by zero length rotational spring elements with very small stiffness. To make sure the equivalent structural properties of the assembly is the same as the actual frame members, the properties of structural components need to be modified in the analytical model [45]. The first three modal periods, pushover and collapse fragility curves of the simulating model of the steel frame are consistent with the results in Lignos and Krawinkler [36].

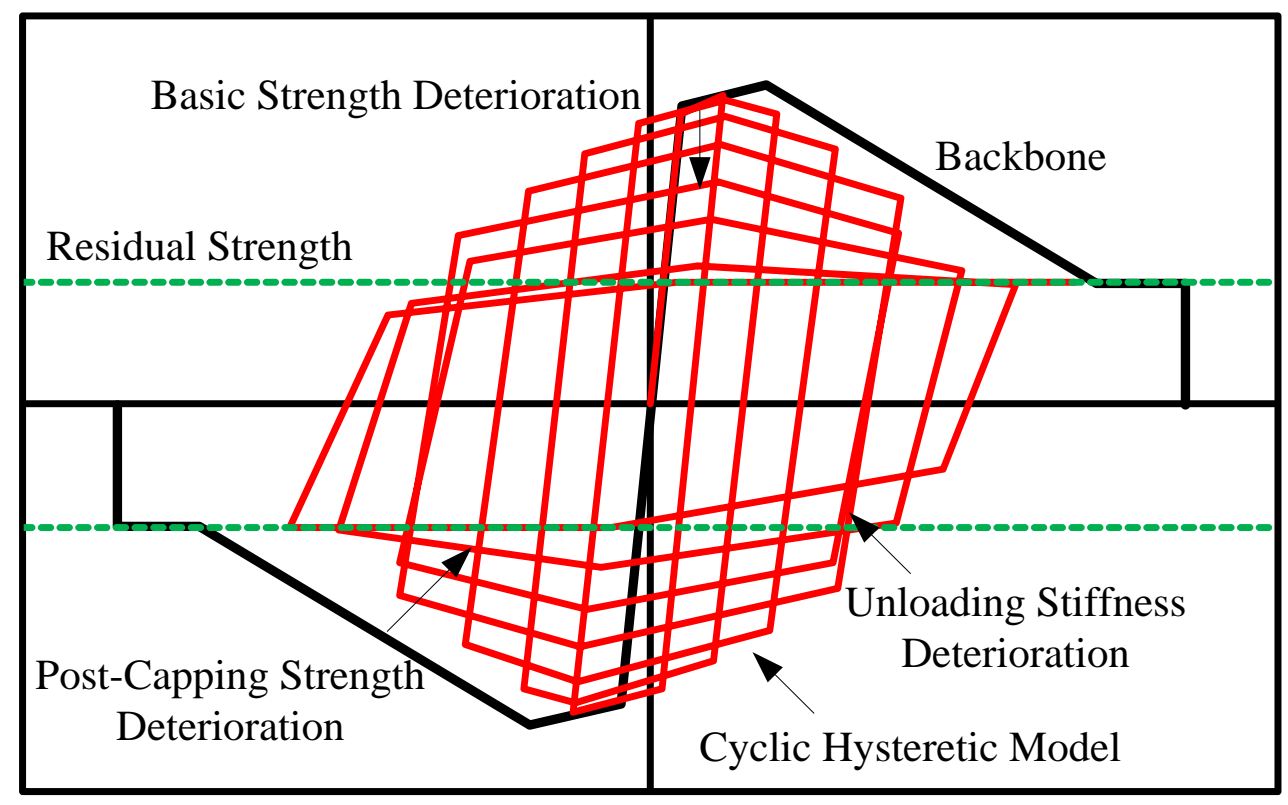

Figure 4. Modified Ibarra Krawinkler Deterioration Model

The site of the four-story steel moment-resisting frame building was assumed to be located in Los Angeles $\left(34.11^{0} \mathrm{~N}, 118.55^{\circ} \mathrm{W}\right)$, a typical urban California site with high levels of seismicity. A site class D soil is assumed and the maximum considered earthquake (MCE) spectral response acceleration is $1.5 \mathrm{~g}$ and $0.9 \mathrm{~g}$, at short periods $\left(S_{D S}\right)$ and at 1-second period $\left(S_{D 1}\right)$, respectively. Thus, the design spectral response accelerations at $S_{D S}$ and $S_{D 1}$ are $1.0 \mathrm{~g}$ and $0.6 \mathrm{~g}$, respectively. 


\section{Simulation of Mainshock-Aftershock Sequences}

In this paper, the synthesized mainshock-aftershock sequences are generated based on earthquake databases and ground motion models. The variability in seismic loading has a significant impact on structural performance in an earthquake event. A general far-field record set in ATC-63 [46], which includes 44 ground motions, was used as the seed to synthesize the artificial mainshock-aftershock sequences. It is assumed that the distribution of spectral acceleration for the earthquakes is lognormal [46]. The median spectral acceleration and dispersion for mainshock and aftershock can be determined by an empirical ground motion model. In this study, the ground motion model developed by Abrahamson and Silva [47] is used, which is applicable to M5-8.5, source-to-site distance 0-200km, and spectral periods 0-10 sec.

The occurrence time and the magnitude of the mainshock and aftershock can be determined by the empirical laws, which are well-supported by real data, e.g., the Gutenberg-Richter law, modified Omori's Law, and Bath's Law. The occurrence of the mainshock is typically simulated as a homogeneous Poisson process, while the aftershock occurrence as a nonhomogeneous Poisson process [26,48-50].

Applying the Gutenberg-Richter law [51], the probability-density function of earthquake magnitude $(M)$ can be determined as:

$$
f_{M}(m)=\frac{b \ln (10) 10^{-b\left(m-m_{\min }\right)}}{1-10^{-b\left(m_{\max }-m_{\min }\right)}}
$$

where $M_{\min }$ and $M_{\max }$ are the minimum and maximum magnitudes at a region, respectively. $\mathrm{b}$ is the region-specific parameter.

Based on the modified Omori's Law [52, 53], the mean daily rate of aftershock can be obtained as:

$$
\lambda(t)=\frac{10^{a+b\left(M_{u}-M_{l}\right)}-10^{a}}{(t+c)^{p}}
$$

where, $\lambda(t)$ is mean daily rate of aftershock with a magnitude between $M_{l}$ and $M_{u} . M_{l}$ and $M_{u}$ are minimum and maximum magnitudes of aftershock, respectively.

In this study, $M_{l}$ is typically taken as $5.0[10,54] . M_{u}$ is usually considered to be the mainshock magnitude $M_{m}$ (e.g. [57]). The site-specific parameters in Eq. (2) for California are taken to be $a=-1.67, b=0.91, p=1.08$, and $c=0.05[8,9]$. Based on the mean daily rate of aftershocks, the 
aftershock successive arrival times $T_{1}, T_{2}, \ldots, T_{n}$ of the nonhomogeneous Poisson process can be generated by the rejection method [26, 56,57].

Figure 5 shows the simulated occurrence time of aftershocks having magnitude 5 or greater, following a mainshock with magnitude 7.5. The x-coordinate of a circle indicates the elapsed time between the aftershock and mainshock, the y-coordinate indicates the site-to-source distance of the aftershock, whereas the $\mathrm{z}$ - coordinate is the magnitude of the aftershocks. In recent earthquakes, it has been shown that the magnitude of the aftershocks have a weak correlation with the occurrence time. For simplicity, it is assumed that the magnitudes of aftershocks are characterized by the Gutenberg-Richter relationship, while the source-to-site distances are uniformly distributed between 10 and $100 \mathrm{~km}$ [26,54]. From Figure 5, it can be seen that most aftershocks occur within a month after the mainshock and the number of aftershocks reduces significantly as time passes.

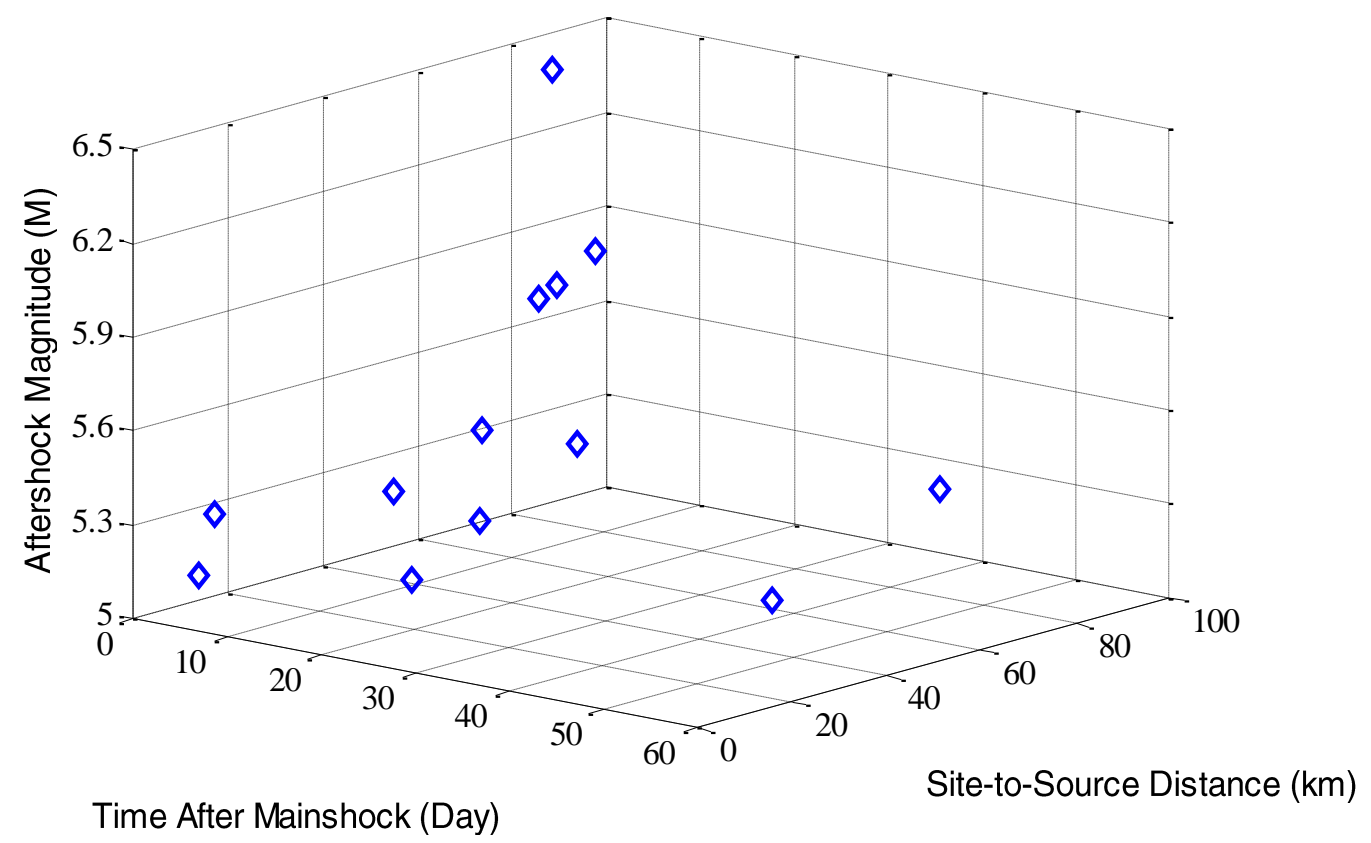

Figure 5. Simulated aftershocks following a mainshock with magnitude 7.5 (only aftershocks with magnitude 5 or greater are considered)

Given the magnitude and site-to-source distance of a shock, the target spectral acceleration of an earthquake record can be determined by the ground motion model. There is uncertainty for the ground motion model, because the model was developed using idealized data with respect to physical processes of generation and propagation of seismic waves through a regression process [58]. This uncertainty is not considered in current study. Then a ground motion record is randomly selected in the far-field record set and the earthquake intensity is scaled to the target intensity level. Based on the occurrence time of shocks, the mainshock-aftershock sequences are 
generated by combining the selected and scaled shocks in the ordered sequences. It should be noted that the above method of constructing mainshock-aftershock sequences from the far-field record set assumes that the response spectral shapes (i.e. relative frequency content) for mainshocks and aftershocks are identical. In some cases, recorded aftershocks may have less rich long-period frequency content than recorded mainshocks. The method proposed in current paper uses the simulated mainshock-aftershock sequences to demonstrate the effect of considering aftershock hazard on seismic loss estimation for building structures. Using recorded mainshockaftershock sequences in loss estimation is a subject for future study.

\section{Seismic Fragility Models}

For the purpose of structural damage identification and seismic loss estimation, the engineering demand parameters must be related to a measure of earthquake intensities [9]. In this study, the maximum interstory drift is adopted as the engineering demand parameter, and the earthquake intensity is the spectral acceleration at the fundamental period of the structural model. By performing nonlinear time history analysis, the relationship between peak drift and spectral acceleration can be established using numerous ground motions at different intensity levels [60]. The median relationship between spectral acceleration and peak drift can be modeled by the form [61].

$$
D=a\left(S_{m}\right)^{n}
$$

in which $D$ is the maximum interstory drift, $S_{m}$ is the spectral acceleration. $\mathrm{m}$ and $\mathrm{n}$ are the constants, which can be determined by a regression analysis of the peak drifts. The three ground motion sets for Los Angeles developed in the SAC Project Phase 2 [62] are used in this study to develop the relationship between $D$ and $S_{m}$ for the 4-story building. This ground motion suite is used because compared to the 44 ground motions in far-field record set in ATC-63 [46] which ranges from $0.07 \mathrm{~g}$ to $0.66 \mathrm{~g}$, they have a much wider range of intensity levels at the structural fundamental period, from $0.1 \mathrm{~g}$ to $1.76 \mathrm{~g}$. The three sets include 60 ground motions corresponding to three earthquake hazard levels, i.e. having probabilities of exceeding 50\% (la41-60), 10\% (la01-20), 2\% (la21-40) in 50 years, respectively. The nonlinear dynamic analysis for the fourstory steel building model is conducted using OpenSees [42].

Figure 6 presents the relationship between maximum interstory drift and spectral acceleration expressed in Equation (3). The $D-S_{m}$ pairs for three ground motion sets: $50 \%, 10 \%$ and $2 \%$ in 50 years, are represented by diamond-shaped, square and triangular markers, respectively. It shows that the maximum drift generally increases as the hazard level of earthquake increases. The different sets of ground motion have no significant effect on the relationship between peak drift and spectral acceleration. The finding is consistent with the observations in other studies $[59,60]$. 
The seismic drifts can be described by the lognormal distribution with the median value defined in Equation (3) and logarithmic standard deviation $\beta_{D \mid S_{m}}$ (also called dispersion of seismic demand due to record-to-record uncertainty $\beta_{r 2 r}$ ) as defined by the scatter around median [61]. From the regression analysis of all $60 D-S_{m}$ pairs shown in Figure 6, the value of parameters $m$ and $\mathrm{n}$ are determined as 0.048 and 0.775 , respectively, and logarithmic standard deviation $\beta_{D \mid S_{m}}$ is 0.36. These values agree well with the findings for the steel building in Luco and Cornell [60].

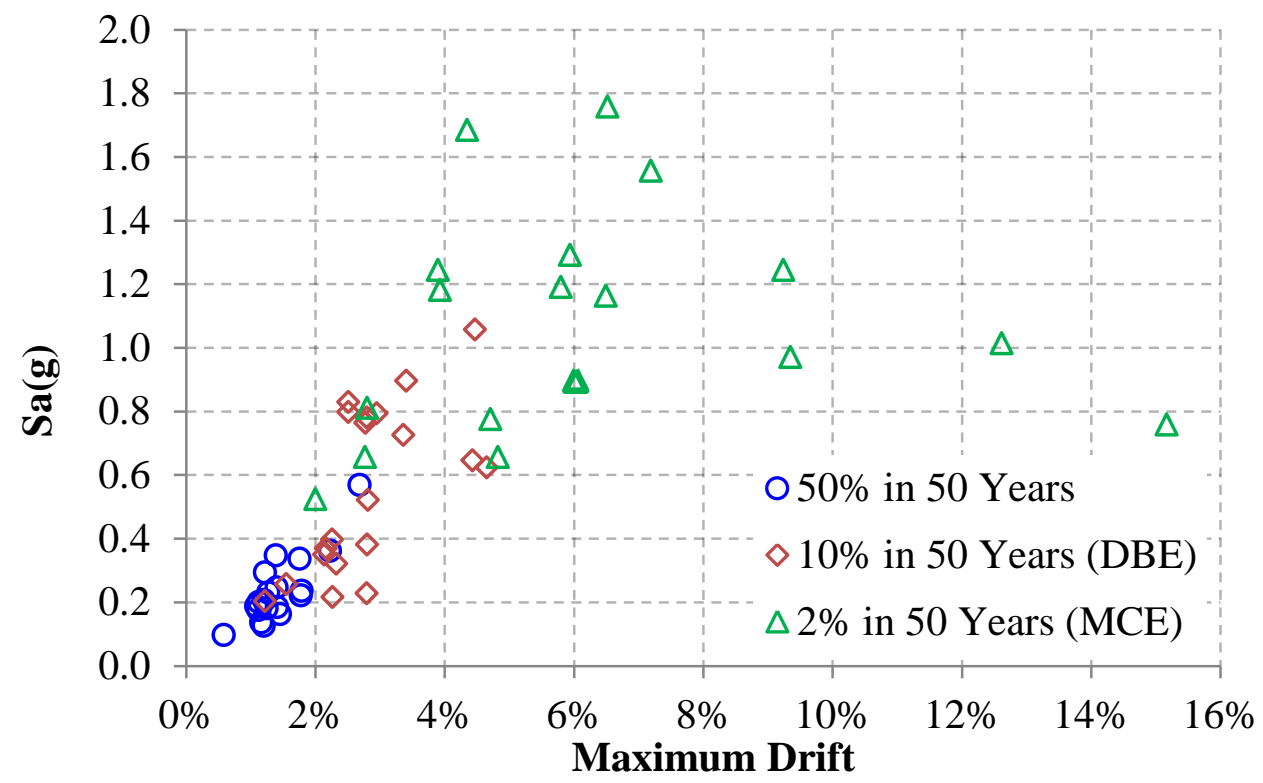

Figure 6. Maximum drift vs. $S_{a}$

The probability of exceeding drift limits associated with the stipulated performance levels of building (denoted by the fragility) can be obtained by

$$
P(D \geq d)=1-\Phi(\ln (d / D) / \beta)
$$

in which, $\Phi()$ is the standard normal distribution and $\beta$ is the dispersion of the structural fragility. $D$ is the peak drift from structural nonlinear dynamic analysis and $d$ is specified structural damage states. Five damage states (DS) are used in this study, including the undamaged state (DS0), three damage states (DS1, DS2 and DS3) defined in ATC-58 [16], and a structural collapse state (DS4). For steel ductile moment resisting frame [16], the values of median drift $1.5 \%, 2.7 \%$ and $4.1 \%$ correspond to damage states DS1, DS2 and DS3, respectively.

The median drift value and the standard deviation corresponding to the collapse state (DS4) for the four-story steel frame building can be obtained by the incremental dynamic analysis (IDA) $[63,64]$. An IDA shown in Figure 7 involves a series of nonlinear dynamic time history analysis 
of the building subjected to an ensemble of ground motion records, each record being scaled to multiple seismic levels. The 44 ground motions in the far-field record set in FEMA P695 [46] and the 60 earthquake records for Los Angeles in the SAC Project Phase 2 [62] are employed to determine the structural collapse capacity. In this study, the structural collapse capacity is defined as the last point on the IDA curve that is larger than the initial $20 \%$ tangent slope of the curve [54]. The median collapse drift for the building is determined as $8.4 \%$ with the standard deviation $\beta_{r 2 r}=0.40$.

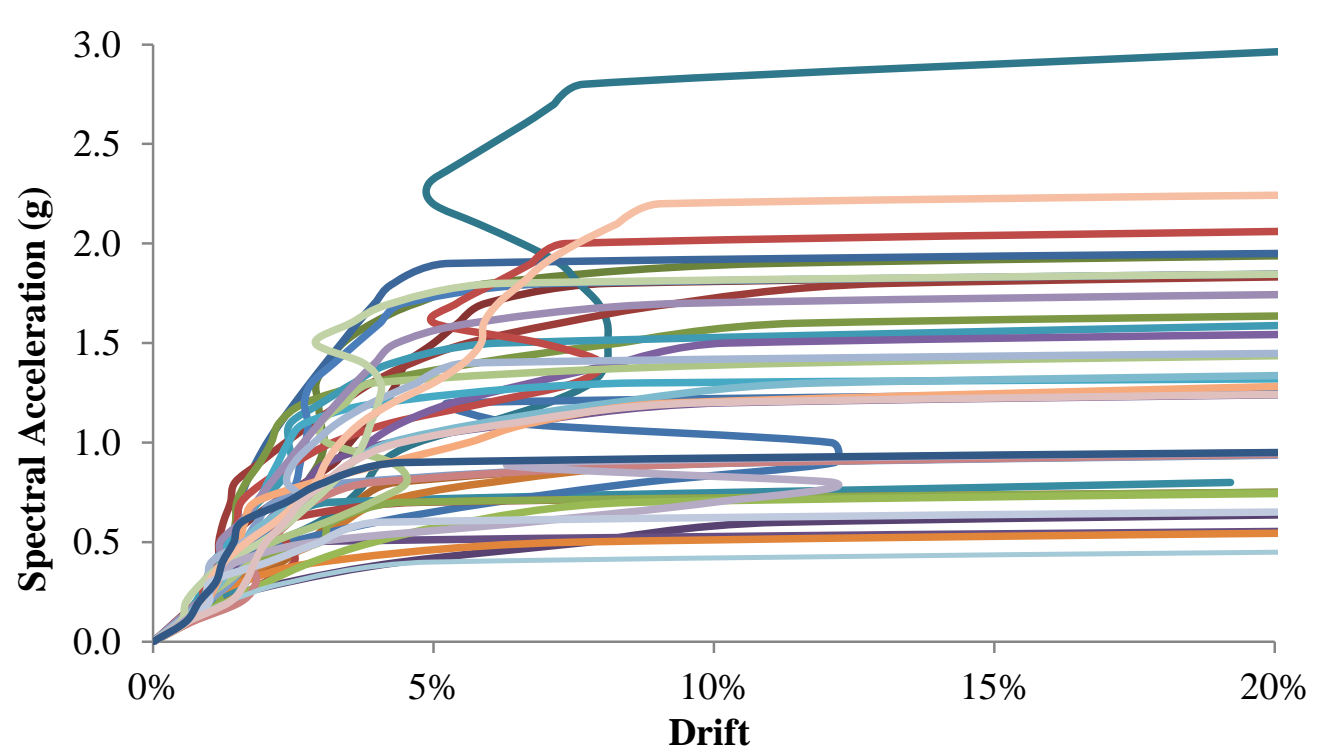

Figure 7. IDA curves for the four-story steel frame moment building

In this study, the structural fragility dispersion $\beta$ is accounted for based on two sources of uncertainty: record-to-record uncertainty and modeling uncertainty. The record-to-record uncertainty accounts for the variation in seismic demand among different ground motion records. The modeling uncertainty results from the inaccuracies in structural component modeling, properties of elements, and the simplified assumptions. It can be classified into two types: uncertainties associated with building definition and construction quality assurance, and uncertainties with model quality and completeness [16]. The default dispersion of modeling uncertainty is provided in ATC-58 [16] and the dispersion 0.4 is adopted for the calibrated steel structure to account for modeling uncertainty.

The total dispersion can be estimated by the square-root-sum-of-squares (SRSS) method [61]. Using the SRSS method, the structural fragility dispersion considering both record-to-record uncertainty and modeling uncertainty can be determined by

$$
\beta=\sqrt{\beta_{r 2 r}^{2}+\beta_{m}^{2}}
$$


where $\beta$ is the total fragility dispersion, $\beta_{r 2 r}$ is the dispersion due to record-to-record uncertainty, and $\beta_{m}$ is the dispersion of modeling uncertainty. The related dispersion quantities are listed in Table 1.

Table 1. Parameters of damage state fragilities

\begin{tabular}{|c|c|c|c|c|}
\hline Damage States & Median drift (\%) & $\beta_{r 2 r}$ & $\beta_{m}$ & $\beta$ \\
\hline DS1 & 1.5 & 0.36 & 0.40 & 0.54 \\
\hline DS2 & 2.7 & 0.36 & 0.40 & 0.54 \\
\hline DS3 & 4.1 & 0.36 & 0.40 & 0.54 \\
\hline DS4 & 8.4 & 0.40 & 0.40 & 0.57 \\
\hline
\end{tabular}

The damage state fragility curves of DS1, DS2, DS3 and DS4 (shown in Figure 8) can be obtained by applying Equation (4). Given a maximum interstory transient drift such as 3\%, the exceeding probability of DS1, DS2, DS3 and DS4 can be determined as $0.900,0.577,0.281$ and 0.035 from Figure 8 . The five damage states in this study are sequential damage states therefore one damage state cannot occur until the prior, less severe state has occurred. A uniform number $u \in(0,1)$ is generated to serve as the basis for determining the damage state [16]. A range of number is assigned to each sequential damage state. For example, in the case that the structural peak drift is $3 \%$, the building is in the DS0 if $u \geq 0.900$, DS1 if $0.577 \leq u \leq 0.900$, DS2 if 0.281 $\leq u \leq 0.577$, DS3 if $0.035 \leq u \leq 0.281$, or DS4 if $u \leq 0.035$. Once the damage state is identified, the seismic losses can be computed as described in the following section.

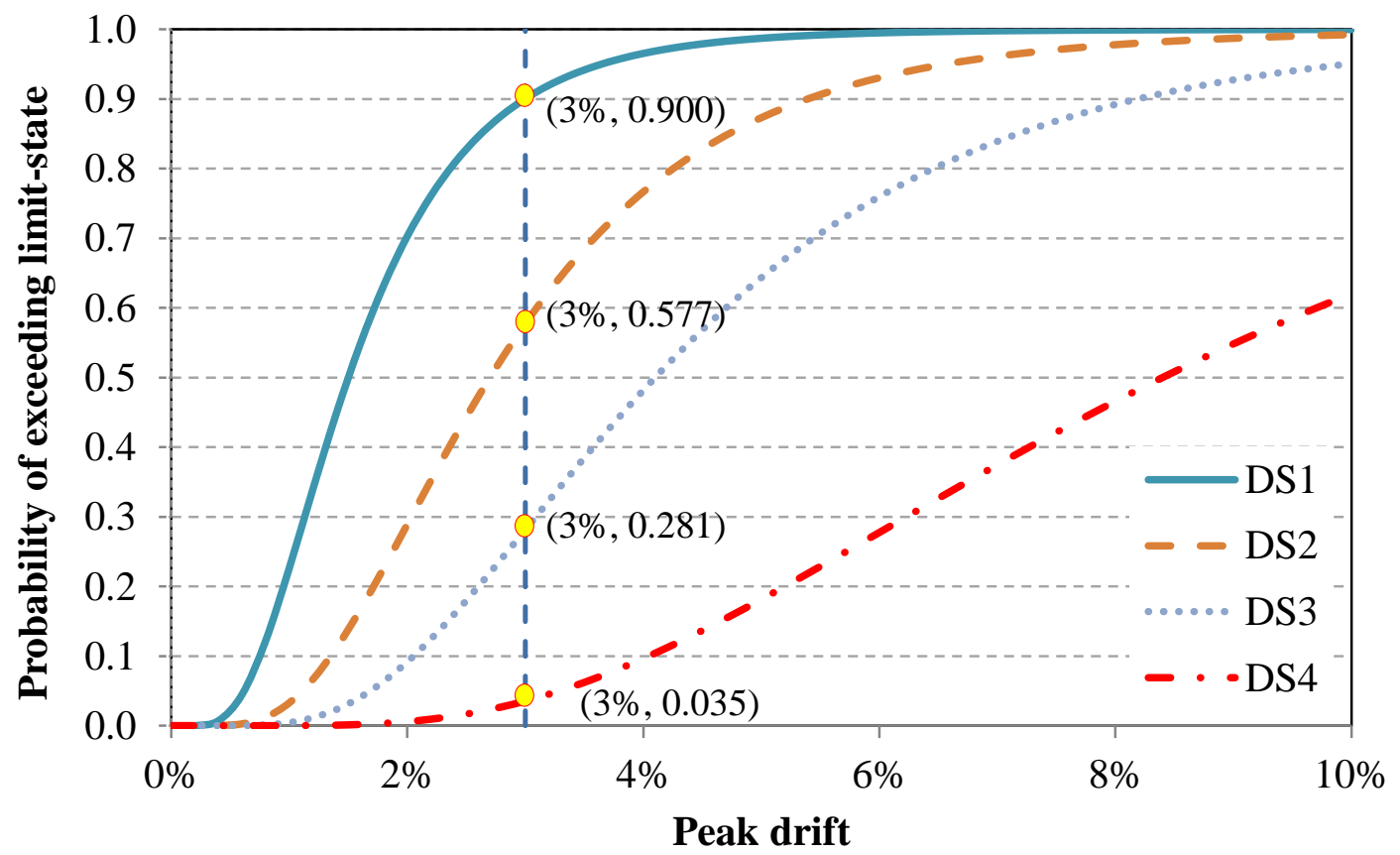

Figure 8. Damage state fragility of the four-story steel building 


\section{Earthquake Damage States and Seismic Loss}

The earthquake loss is typically quantified as a percentage of building replacement value (denoted by the loss ratio), which is the cost needed to completely replace a damaged building. The replacement costs for the four-story steel frame building located in Los Angeles can be calculated by multiplying the total story area by the unit construction cost. According to Lignos and Krawinkler [36], the area of typical floor was $1003.4 \mathrm{~m}^{2}$ and the total area is derived as $4013.4 \mathrm{~m}^{2}$. The construction cost is estimated to $\$ 1952.31 / \mathrm{m}^{2}$ for two-to-four story office in Los Angeles [65]. Taking into account the content value as 50\% of replacement cost, the total replacement value (TRV) is about $\$ 11.75 \mathrm{M}$. The downtime cost can be derived from the total building area and the unit rent fee. The average rental rates for Los Angeles for an office during the final quarter of 2012 was $\$ 379.98 / \mathrm{m}^{2}$, and the unit daily rent fee for the building was $\$ 4.22 /$ $m^{2}$ [66]. The downtime cost per day for the commercial building is $\$ 16,934,0.144 \%$ of TRV.

The seismic losses including transition cost (TC) and downtime cost (DC) are considered in this study. Table 2 lists the transition and downtime costs. Assuming no repair is undertaken prior to the aftershock, transition costs for $D S_{i} \rightarrow D S_{j}(i \geq j)$ are not applicable. The data listed in Table 2 was derived for a commercial steel frame building [10]. The probability of limited function for downtime cost is taken into account. For example, it is assumed that the building has $10 \%$ of function to be restricted in the three days even if the structure is intact after the earthquake. The parameters of the cost model in Table 2 are based on several assumptions due to a lack of seismic loss information, and thus it is recognized that improved cost models need to be taken into account in the further studies as information becomes available.

Table 2. Transition and Downtime Costs for various Damage States

\begin{tabular}{|c|c|c|c|c|c|c|c|}
\hline \multirow{2}{*}{ Damage state } & \multicolumn{4}{|c|}{ Transition Cost } & \multicolumn{2}{c|}{ Downtime } \\
\cline { 2 - 8 } & DS0 & DS1 building replacement) & DS2 & DS3 & DS4 & Days & $\begin{array}{c}\text { Probability of } \\
\text { limited function }\end{array}$ \\
\hline DS0 & n/a & 25 & 50 & 75 & 100 & 3 & $10 \%$ \\
\hline DS1 & n/a & n/a & 25 & 50 & 75 & 6 & $50 \%$ \\
\hline DS2 & n/a & n/a & n/a & 25 & 50 & 10 & $75 \%$ \\
\hline DS3 & n/a & n/a & n/a & n/a & 25 & 100 & $100 \%$ \\
\hline DS4 & n/a & n/a & n/a & n/a & n/a & 500 & $100 \%$ \\
\hline
\end{tabular}

\section{Simulation Framework for Seismic Loss Assessment Considering Aftershocks}

The MCS is applied to examine the uncertainty of loss estimation in this study. Four main sources of uncertainties and the propagation in the MCS approach are discussed, including the record-to-record uncertainty, modeling uncertainty, damage state uncertainty given an EDP, and 
cost estimation uncertainty conditioned on DS. Based on the ground motion model, the recordto-record uncertainty is taken into account by sampling a large number of earthquake scenarios with different magnitudes and source-to-site distance. The damage state uncertainty given an EDP has been incorporated in damage state fragilities (Figure 8). The uncertainties of both transition cost and downtime cost conditioned on DS are assumed as 0.30 .

The Latin Hypercube Sampling (LHS) technique was applied within the MCS in this study to reduce the computational demand and improve the accuracy of the loss estimation. The sampling number $N$ can be significantly reduced by using the LHS in classic MCS while keeping the same accuracy level [66-68]. For the case that each of $k$ variables needs to be generated $n$ sampling numbers, the range of each variable firstly is divided into $n$ nonoverlapping intervals with equal probability. Then one value is randomly selected in each interval and a $n \times k$ matrix sample is generated for $k$ variables by applying LHS technique. The details of procedure can be found in Iman et al. [69,70].

Based on the modified Omori's Law [53] that the number of aftershocks is decreased dramatically as the elapsed time increases, the aftershock hazard in seven days is firstly taken into account to estimate the intensity-based seismic losses given a seismic level of earthquake mainshock. The expected seismic loss of the building subjected to two levels of earthquakes including the Design Earthquake (DE) and the Maximum Considered Earthquake (MCE), and the following aftershocks in the seven days after mainshock are investigated in this study.

Since the first fundamental period of the four story building is 1.32 seconds, the spectral response acceleration $S_{a}\left(T_{1}\right)$ for $\mathrm{DE}$ and $\mathrm{MCE}$ is $0.45 \mathrm{~g}$ and $0.68 \mathrm{~g}$, respectively. With the assumption of $10 \mathrm{~km}$ source-to-site distance for the mainshock, the magnitudes of earthquake by the ground motion model [47] are determined as 7.2 and 7.5 corresponding to the DE and MCE, respectively. To generate the following aftershocks over 7 days, the minimum magnitude is assigned a value of 5.0, and the source-to-site distance is assumed to be uniformly distributed between 10 and $100 \mathrm{~km}$.

MCS is performed for the two intensity levels of earthquake. 10,000 runs for MCS are carried out for each case in the following scheme, as shown in Figure 9. For each seismic intensity level, the simulation of mainshock-aftershock sequences and structural analysis objects are executed in the outer loop 100 times (i.e. $\mathrm{NMC1=100)} \mathrm{to} \mathrm{take} \mathrm{into} \mathrm{account} \mathrm{the} \mathrm{record-to-record} \mathrm{uncertainty.}$ For the $i^{\text {th }}$ outer loop, sequences of mainshock and aftershock are simulated by scaling intensity of the ground motions which are randomly selected from the far-field bin in ATC-63 [46] to the target values. The far-field bin includes 44 ground motions with magnitude between 6.5 and 7.6, which are carefully selected to represent the record-to-record uncertainty [46]. By performing the nonlinear dynamic analysis, the peak interstory drifts attributed to the mainshock and the following aftershocks can be obtained and then feed into the inner loop, where the 100 runs of 
loss analysis are carried out. For the $j^{\text {th }}$ inner loop in the $i^{\text {th }}$ outer loop, the damage state uncertainty given a EDP and cost estimation uncertainty conditioned on DS are sampled by performing the MCS with LHS. A series of damage states, transition and downtime cost are obtained and noted as $\mathrm{DS}\left(t_{i, 1}, j\right), \mathrm{DS}\left(t_{i, 2}, j\right), \mathrm{DS}\left(t_{i, 3}, j\right), \ldots ; \mathrm{TC}\left(\mathrm{DS}_{1, j} \rightarrow \mathrm{DS}_{2, j}\right), \mathrm{TC}\left(\mathrm{DS}_{1, j} \rightarrow \mathrm{DS}_{3}\right.$, $j), \cdots ; \operatorname{DC}\left(\operatorname{DS}_{1, j}\right), \operatorname{DS}\left(\mathrm{DS}_{2, j}\right), \cdots$, respectively. Then the transition and downtime costs can be determined and denoted as $\mathrm{TC}\left(t_{i, 1}, j\right), \mathrm{DC}\left(t_{i, 1}, j \rightarrow t_{i, 2}, j\right), \mathrm{TC}\left(t_{i, 2}, j\right), \mathrm{DC}\left(t_{i, 2}, j \rightarrow t_{i, 3}, j\right), \cdots$. The total loss is then calculated as

$$
\operatorname{Loss}(i, j)=\sum_{m=1}^{N S(i)} \mathrm{TC}\left(t_{i, m}, j\right)+\sum_{n=1}^{N S(i)-1} \mathrm{DC}\left(t_{i, n} \rightarrow t_{i,(n+1)}, j\right)
$$

At the end of the simulation, a matrix of loss values with the dimension NMS1 by NMS2 is obtained. Finally, the expected seismic loss and its uncertainty can be determined by calculating the matrix mean value and dispersion. 


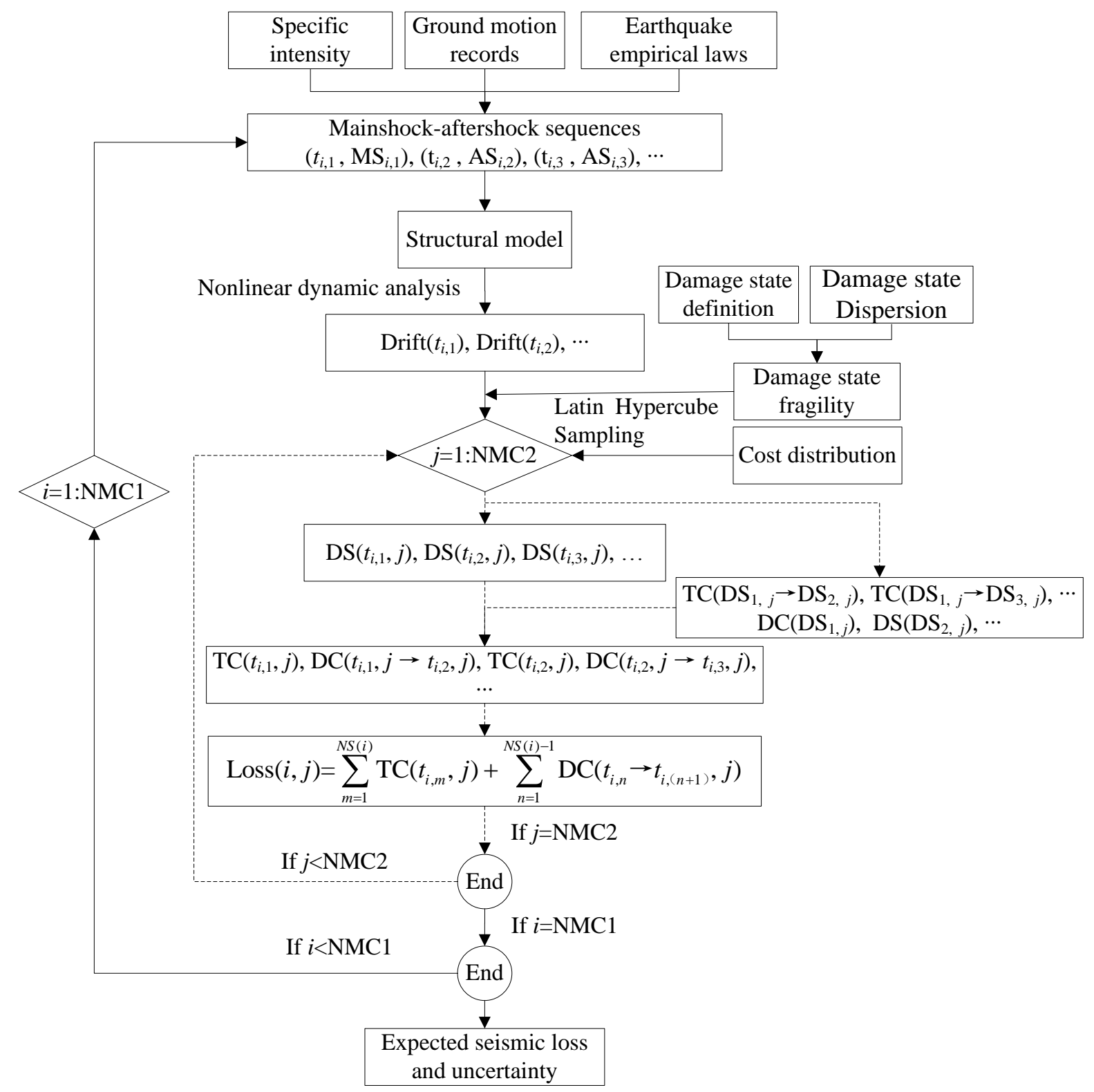

AS=Aftershock $\quad$ MS=Mainshock $\quad$ DS=damage state $\quad$ TC=Transition cost $\quad$ DC=Downtime cost $\mathrm{NC}=$ number of shocks $\quad \mathrm{NMC1}, \mathrm{NMC} 2=$ Number of Monte Carlo Simulation in the outer and inner loop $t=$ Occurring time of shock $\longrightarrow$ Outer loop Inner loop

Figure 9 Monte Carlo simulation with LHS flowchart for seismic loss estimation to MS-AS sequences 


\section{Results and Discussions}

Figure 10 shows the peak drift of the building subjected to mainshock only and subjected to MSAS sequence at DE level. As mentioned earlier, a total of 100 MS-AS sequences are simulated to consider the record-to-record uncertainty. It is noted that most of points are overlapped and there is no obvious difference in the peak drift between the mainshock only and MS-AS sequence, indicating that the aftershocks have no significant influence on the structural behavior at DE level. This observation is also evident in the examination of the expected peak drift for the two cases. The expected peak drift for mainshock is $2.6 \%$, compared to $2.8 \%$ for MS-AS sequence at the DE level.

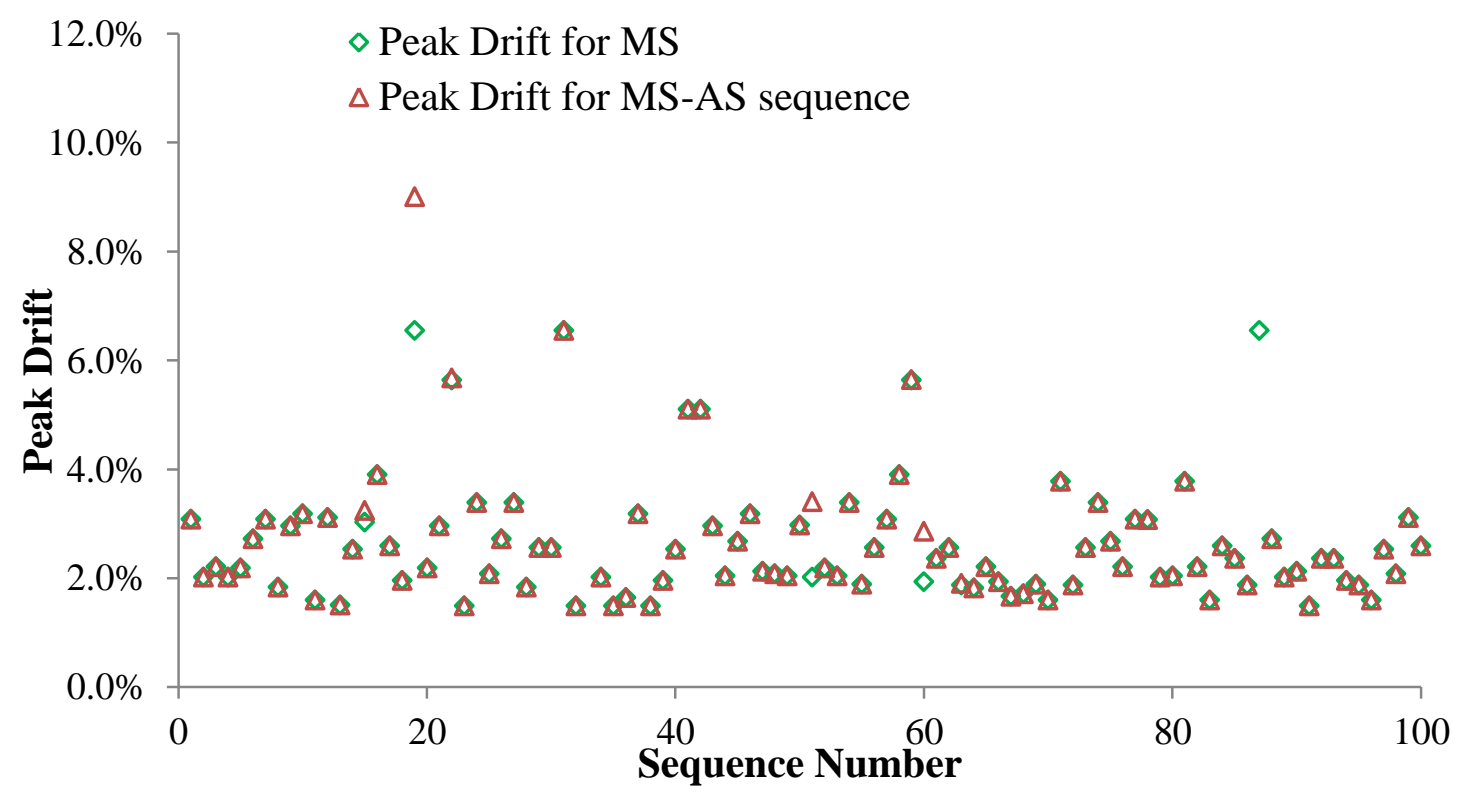

Figure 10. Peak drifts for earthquake MS and MS-AS sequence at DE level

The total loss for mainshock at the DE level and aftershock sequence is presented in Figure 11. The obvious differences can be found by comparison of the total loss between the mainshockonly analyses and the MS-AS sequences, indicating that the aftershocks play a significant role in the assessment of total loss. It is an interesting observation that even if the aftershocks have limited effect on structural behavior, they may still have a significant effect on the seismic loss due to the uncertainty of the damage state and cost estimation. 


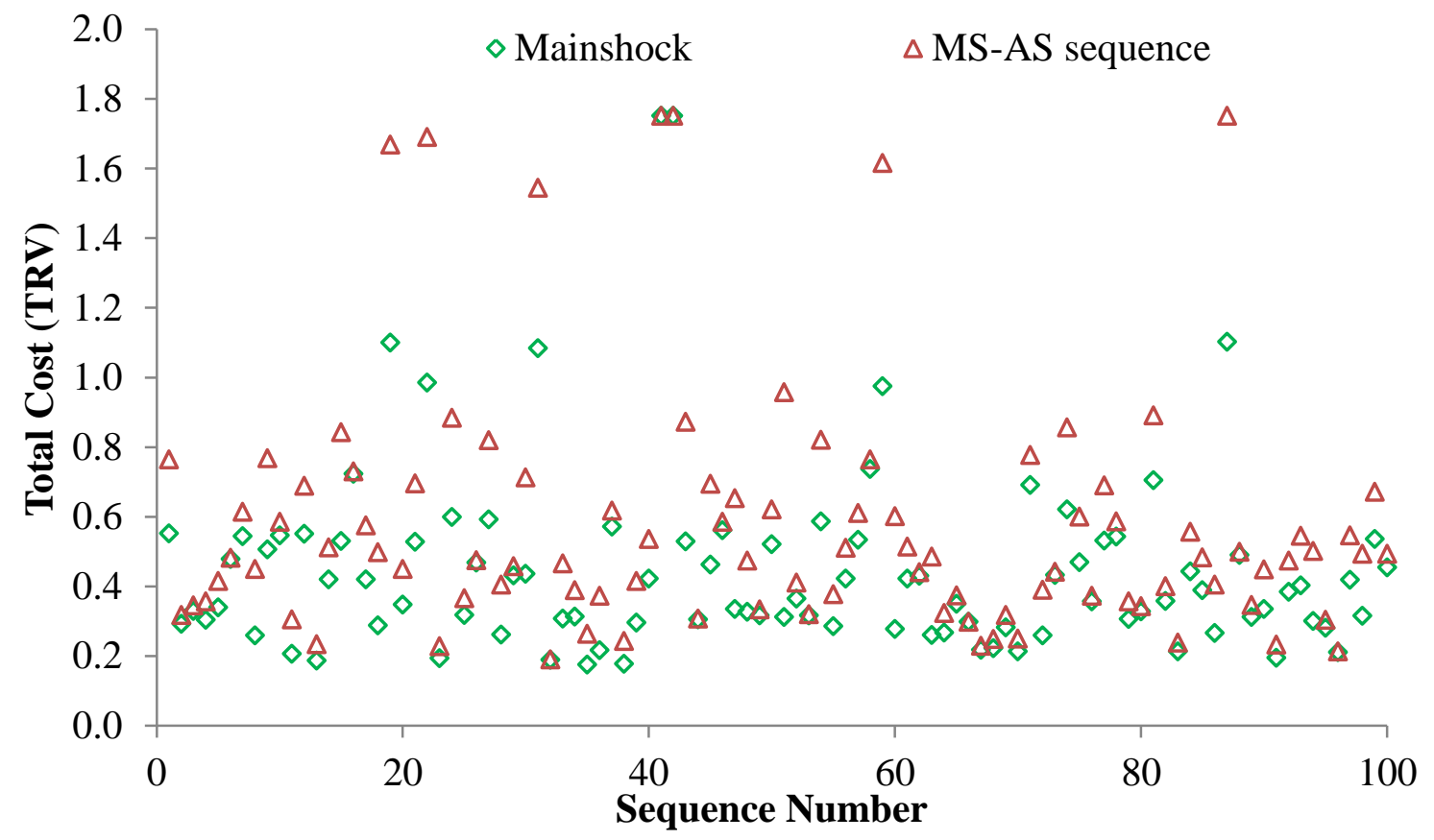

Figure 11. Total loss for earthquake MS and MS-AS sequence at DE level

Figure 12 shows the comparison of expected total loss at the DE and MCE intensity levels. It can be observed that the aftershocks dramatically increase the probability of seismic losses, especially for high intensity mainshocks. For instance, when the aftershocks are taken into accounted, the total financial loss increase from $45 \%$ to $57 \%$ of TRV at DE level, and from $78 \%$ to $109 \%$ of TRV at MCE level, respectively. Additionally, seismic loss without considering aftershock effects has a $73 \%$ increase at MCE, compared to the loss at DE, while the increment of estimated loss increases to $91 \%$ when aftershock impacts are taken into accounted. This demonstrates that the estimated losses not only increase dramatically with the mainshock intensity level, but also increase significantly when aftershock hazards are included. 


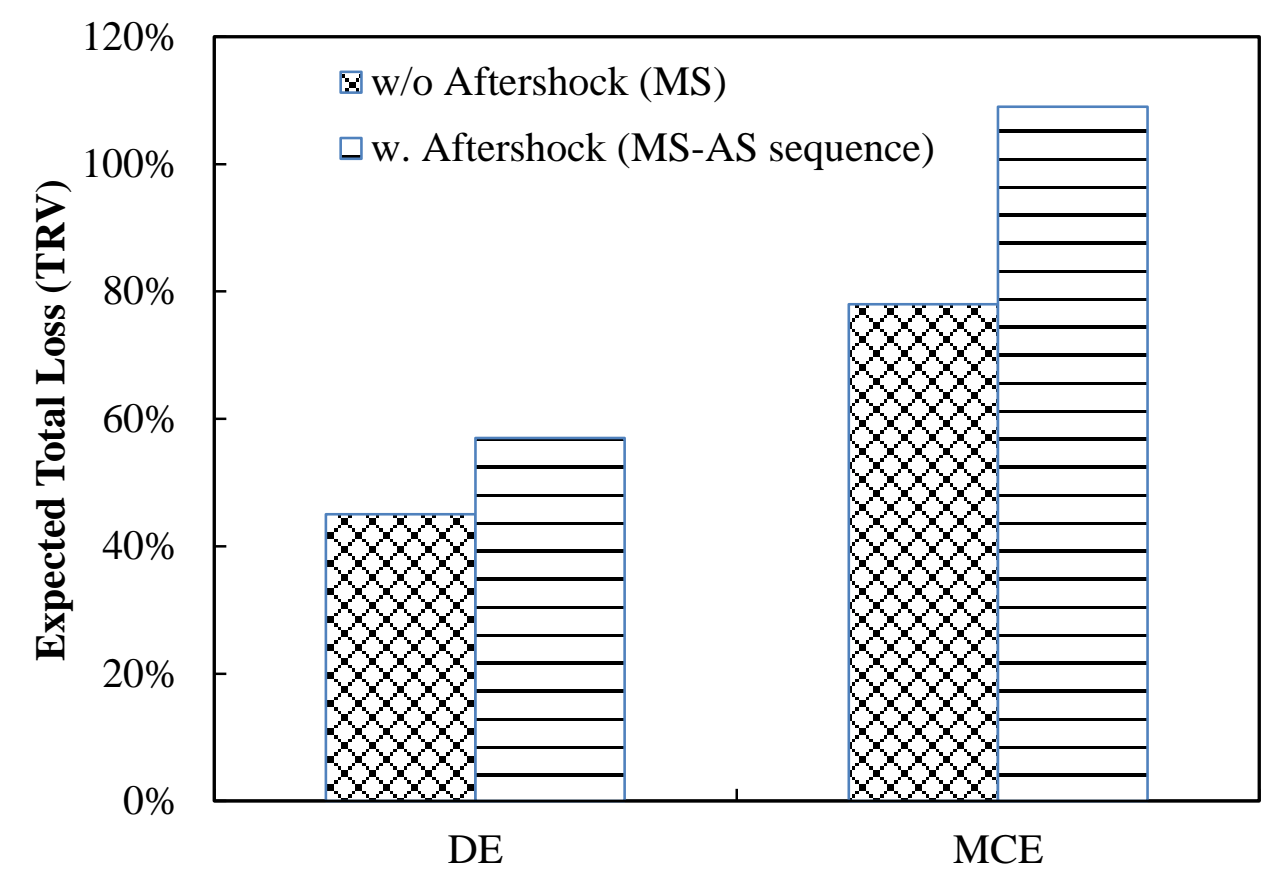

Intensity Level of Earthquakes

Figure 12. Comparison of expected total loss at two seismic intensity levels

The expected loss and the coefficient of variation for mainshock and MS-AS sequence at the DE and MCE levels are listed in Table 3. It indicates that the total losses to MS-AS sequence are $27 \%$ to $40 \%$ higher than those of the MS cases. Given the assumptions in this study, aftershocks have a significant influence on the seismic loss estimation. The observation is consistent with the findings made by other investigators [10]. The transition cost is the main contributor to the losses caused by mainshocks, e.g. for the DE and MCE cases, 74\%-84\% of the loss caused by mainshock are attributed to transition loss. In contrast, the downtime costs become the main contributor to loss caused by aftershocks when the seismic levels increase. For example, at the DE level, 25\% of the loss by aftershocks is attributed to downtime loss, the percentage increases to $42 \%$ at MCE. Additionally, the COV associated with the total expected loss decreases as earthquake intensity increases, from 0.84 at $\mathrm{DE}$ to 0.53 at MCE. The percentile values in terms of TRV of seismic losses given the intensity level of mainshock are listed in Table 4. 
Table 3 Expected losses (\% TRV) of the four-story commercial building in California

\begin{tabular}{|c|c|c|c|c|c|}
\hline \multirow{2}{*}{ Seismic level } & \multirow{2}{*}{ Type of Loss } & \multicolumn{2}{|c|}{ Mainshock } & \multicolumn{2}{c|}{ MS-AS sequences } \\
\cline { 3 - 6 } & & Expected loss & COV & Expected loss & COV \\
\hline \multirow{3}{*}{ DE } & Transition & 38 & 0.82 & 47 & 0.65 \\
\cline { 2 - 6 } & Downtime & 7 & 2.62 & 10 & 2.16 \\
\cline { 2 - 6 } & Total & 45 & 0.99 & 57 & 0.84 \\
\hline \multirow{3}{*}{ MCE } & Transition & 58 & 0.58 & 76 & 0.36 \\
\cline { 2 - 6 } & Downtime & 20 & 1.52 & 33 & 106 \\
\cline { 2 - 6 } & Total & 78 & 0.76 & 109 & 0.53 \\
\hline
\end{tabular}

Table 4 Statistics for seismic losses (\% TRV) given mainshock intensity.

\begin{tabular}{|c|c|c|c|c|c|}
\hline \multirow{2}{*}{ Seismic level } & \multicolumn{5}{|c|}{ Percentile value } \\
\cline { 2 - 6 } & 50 & 75 & 90 & 95 & 99 \\
\hline DE & 44 & 79 & 118 & 170 & 203 \\
\hline MCE & 101 & 162 & 185 & 198 & 226 \\
\hline
\end{tabular}

The uncertainty of loss estimation considering aftershock hazard may have a large dispersion when the buildings suffer from earthquakes with moderate intensity levels, e.g. 0.84 at DE level. In this case, the point estimation cannot provide useful information about the risk of seismic loss for the stakeholders, and the probability distribution of the financial loss can be applied to evaluate the risk of seismic loss. The histograms for economic losses at DE and MCE levels considering mainshock-aftershock sequences are shown in Figure 13 and Figure 14, respectively. It can be observed that the distribution of seismic losses is highly skewed. For example, the seismic losses have $75 \%$ and $95 \%$ probabilities at $79 \%$ and $170 \%$ of TRV when the building is subjected to the earthquakes at DE level, compared to $162 \%$ and $198 \%$ of TRV at MCE level. It is noted that the seismic loss are positive skewed when the seismic intensity is low or moderate, and tend to skew negatively if the intensity of ground motions is high due to the uncertainty in damage states and cost estimation. 


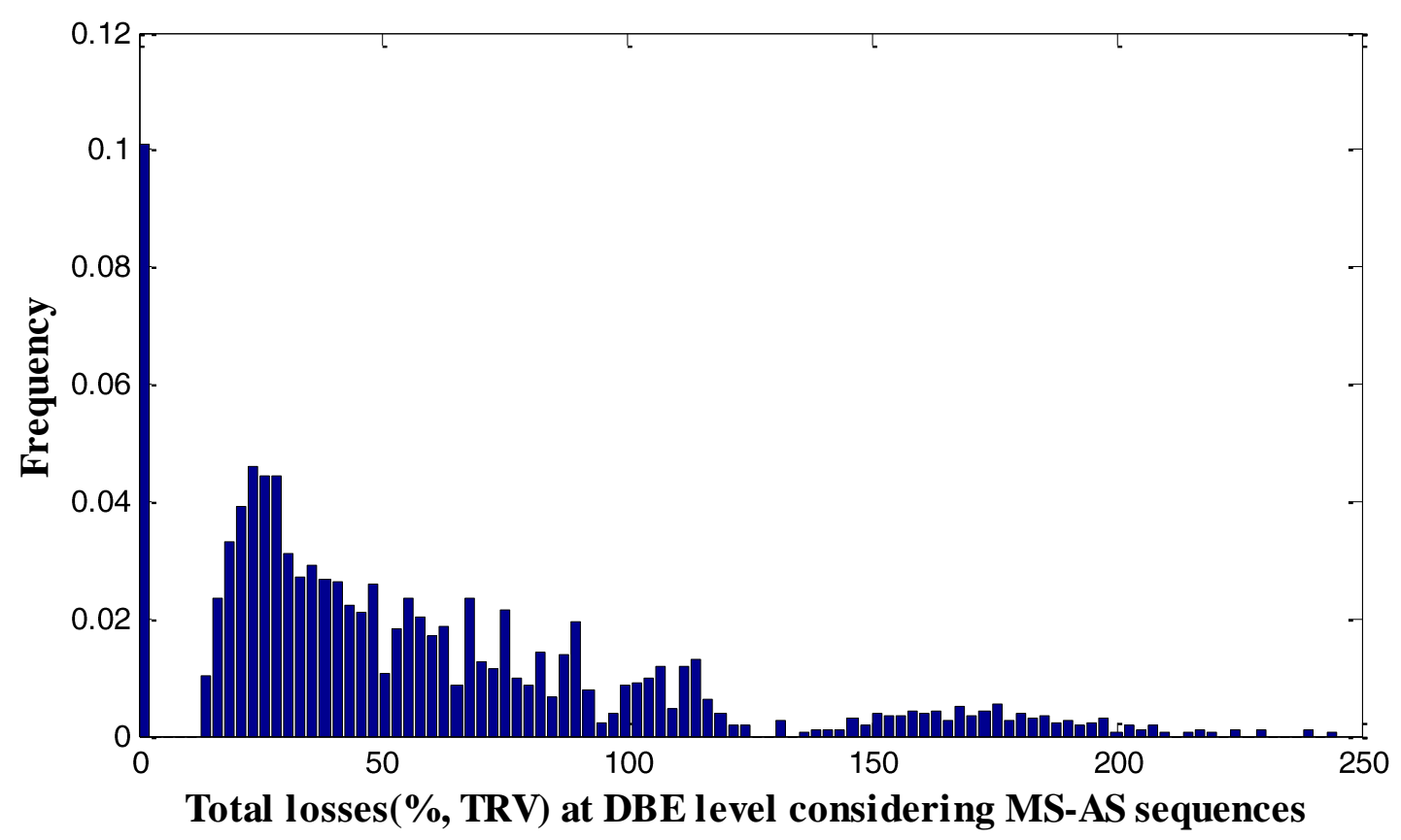

Figure 13. Histogram of economic losses at DE level considering mainshock-aftershock sequences

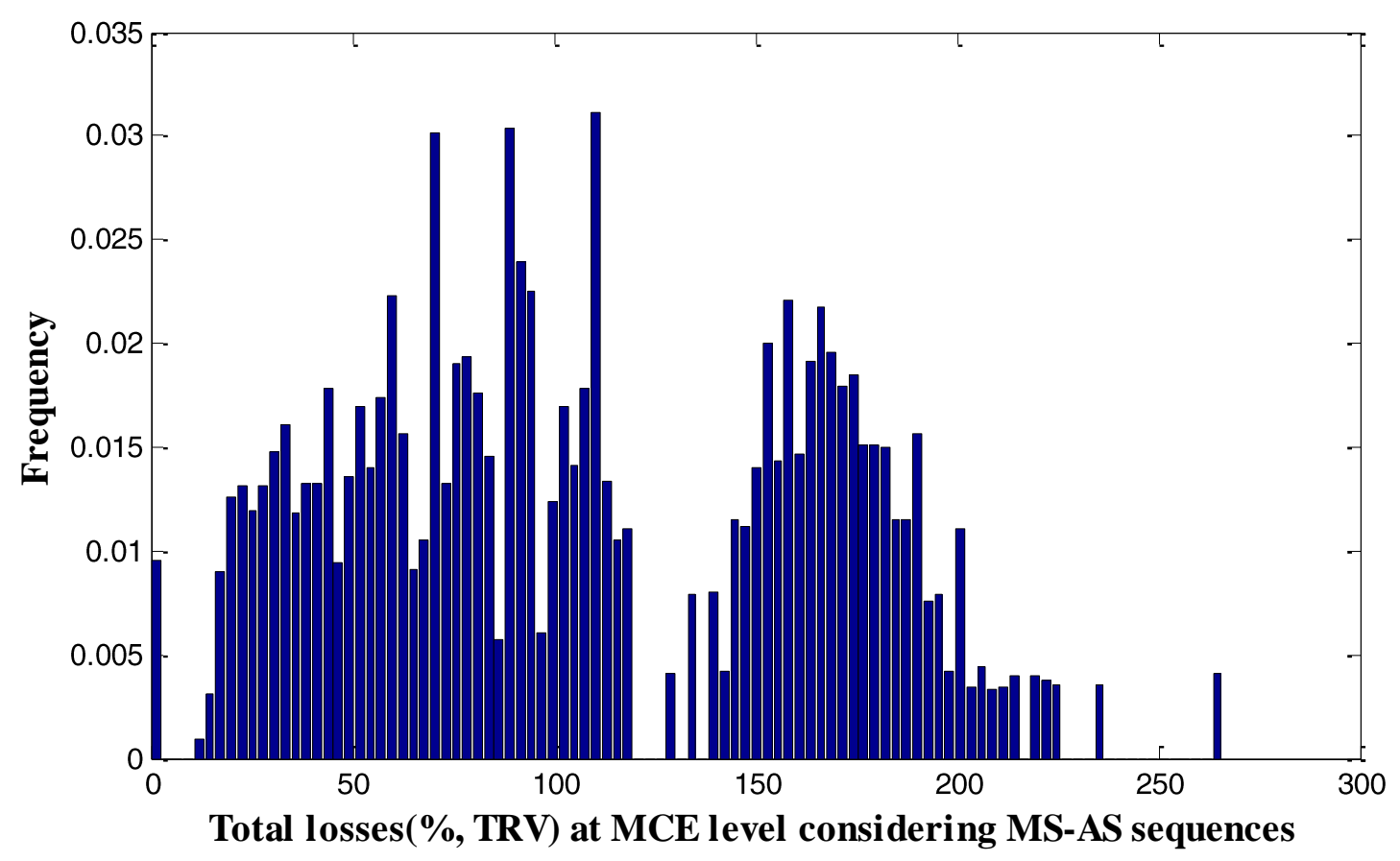

Figure 14. Histogram of economic losses at MCE level considering mainshock-aftershock sequences 


\section{Conclusions}

A framework for loss estimation of steel structures subjected to mainshock-aftershock sequences is proposed and illustrated in this study. The analysis is based on a typical four-story steel frame with a deterioration model and the model has been calibrated using existing data from two tests of a scaled steel structure tested at the SUNY-Buffalo NEES laboratory. The maximum interstory drift obtained in the nonlinear dynamic analysis is employed as the engineering demand parameter to determine the damage states. The proposed framework of seismic loss estimation is applied to examine the effects of aftershocks on seismic loss. The expected seismic loss of the building subjected to two levels of earthquake mainshocks including the Design Earthquake (DE) and Maximum Considered Earthquake (MCE), and the aftershocks in 7 days after the mainshock are examined. Both transition damage cost and downtime cost are considered. Monte Carlo Simulation (MCS) with the Latin Hypercube Sampling (LHS) is applied to examine the uncertainty of loss estimation. It was found that even if the aftershocks have little influence on structural behavior, they may still have a significant effect on the seismic loss due to the uncertainty in the damage states and in the cost estimation. The total losses accounting for mainshock-aftershock sequences are approximately $27 \%$ - $40 \%$ higher than those considering only mainshocks. The dispersion associated with the expected loss uncertainties decreases as the intensity of the mainshock increases.

\section{Acknowledgements}

The research described in this paper was supported, in part, by the National Science Foundation (NSF) Division of Civil, Mechanical, and Manufacturing Innovation (CMMI) under Grant No. CMMI-1100423. The support is gratefully acknowledged. However, the writers take sole responsibility for the views expressed in this paper, which may not represent the position of the NSF or their respective institutions.

\section{References:}

[1] Goda K, Taylor CA. Effects of aftershocks on peak ductility demand due to strong ground motion records from shallow crustal earthquakes. Earthquake Eng Struc. 2012:2311-30.

[2] EERI. Learning from Earthquakes: The Mw 6.4 and Mw 6.3 Iran Earthquakes of August 11, 2012. EERI Special Earthquake Report. Available from:

https://eeri.org/cohost/newsletter/December_2012/Varzaghan_Iran.pdf Earthquake Engineering Research Institute; 2012.

[3] USGS. Magnitude 8.6 - off the west coast of Northern Sumatra. Available from: http://earthquake.usgs.gov/earthquakes/recenteqsww/Quakes/usc000905e.php\#summary: United States Geological Survey; 2012.

[4] USGS. Magnitude 9.0 - near the east coast of Honshu, Japan. Available from:

http://earthquake.usgs.gov/earthquakes/eqinthenews/2011/usc0001xgp/\#summary: United States Geological Survey; 2011. 
[5] Parker M, Steenkamp D. The economic impact of the Canterbury earthquakes. Reserve Bank of New Zealand Bulletin. 2012;75:13-25.

[6] USGS. Magnitude 8.8 - offshore Bio-bio, Chile. Available from: http://earthquake.usgs.gov/earthquakes/eqinthenews/2010/us2010tfan/\#summary: United States Geological Survey; 2010.

[7] RMS. The 2010 Maule, Chile Earthquake: Lessons and Future Challenges. 2011.

[8] Song, R., Li, Y., and van de Lindt, J.W. Impact of Earthquake Ground Motion Characteristics on Collapse Risk of Post-Mainshock Buildings Considering Aftershocks, Engineering Structures, 2014; 81, 349-361.

[9] NIED. strong-motion seismograph networks (K-NET, Kik-net). Available from: http://www.kyoshin.bosai.go.jp/: National Research Institute for Earth Science and Disaster Prevention.

[10] Yeo GL, Cornell CA. Building life-cycle cost analysis due to mainshock and aftershock occurrences. Struct Saf. 2009;31:396-408.

[11] Ramirez CM, Liel AB, Mitrani-Reiser J, Haselton CB, Spear AD, Steiner J, et al. Expected earthquake damage and repair costs in reinforced concrete frame buildings. Earthquake Eng Struc. 2012;41:1455-75.

[12] Ellingwood B. Earthquake risk assessment for building structures. Reliability Engrg \& System Safety 2001;74:251-62.

[13] Liu SC, Neghabat F. Cost optimization model for seismic design of structures. Bell Syst Tech J. 1972;51:2209-25.

[14] Moehle J, Deierlein GG. A framework methodology for performance-based earthquake engineering. Proceedings of the 13th World conference on earthquake engineering2004. p. $3812-4$

[15] Baker JW, Cornell CA. Uncertainty propagation in probabilistic seismic loss estimation. Struct Saf. 2008;30:236-52.

[16] ATC-58. Development of Next Generation Performance-Based Seismic Design Procedures for New and Existing Building, 75\% draft ATC-58-1. Redwood City (CA): Applied Technology Council; 2011.

[17] HAZUS-MH2.1. Technical Manual. Federal Emergency Management Agency. Washington (DC): Federal Emergency Management Agency.

[18] Hazus-MH2.1. Advanced Engineering Building Module (AEBM) Technical and User's Manual. Washington (DC): Federal Emergency Management Agency; 2012.

[19] Porter KA, Kiremidjian AS. Assembly-based vulnerability of buildings and its uses in seismic performance evaluation and risk-management decision-making: SPA Risk LLC; 2000. [20] Goulet CA, Haselton CB, Mitrani-Reiser J, Beck JL, Deierlein GG, Porter KA, et al. Evaluation of the seismic performance of a code-conforming reinforced-concrete frame building - from seismic hazard to collapse safety and economic losses. Earthquake Eng Struc. 2007;36:1973-97.

[21] Haselton CB, Goulet C, Mitrani-Reiser J, Beck J, Deierlein GG, Porter KA, et al. An assessment to benchmark the seismic performance of a code-conforming reinforced-concrete moment-frame building. CA: University of California, Berkeley (CA); 2008.

[22] Mitrani-Reiser J. An Ounce of Prevention: Probabilistic Loss Estimation for Performancebased Earthquake Engineering. Pasadena (CA): California Institute of Technology; 2007.

[23] Ramirez CM, Miranda E. Building-specific loss estimation methods \& tools for simplified performance-based earthquake engineering: Stanford University; 2009. 
[24] Pei S, van de Lindt JW. Methodology for earthquake-induced loss estimation: An application to woodframe buildings. Struct Saf. 2009;31:31-42.

[25] Bradley BA, Lee DS. Accuracy of approximate methods of uncertainty propagation in seismic loss estimation. Struct Saf. 2010;32:13-24.

[26] Yin Y-J, Li Y. Loss Estimation of Light-Frame Wood Construction Subjected to Mainshock-Aftershock Sequences. J Perform Constr Facil. 2011;25:504-13.

[27] Sanchez-Silva M, Klutke G-A, Rosowsky DV. Life-cycle performance of structures subject to multiple deterioration mechanisms. Struct Saf. 2011;33:206-17.

[28] Nazari, N., van de Lindt, J.W. and Li, Y. Quantifying Changes in Structural Design Needed to Account for Aftershock Hazard, Journal of Structural Engineering, ASCE, 2016.

[29]Jeon, Jong - Su, Reginald DesRoches, and Do Hyung Lee. Post - repair effect of column jackets on aftershock fragilities of damaged RC bridges subjected to successive earthquakes. Earthquake Engineering \& Structural Dynamics, 2016.

[30] Han, R., Li, Y., and van de Lindt, J.W. Impact of Aftershocks and Uncertainties on the Seismic Evaluation of Non-Ductile Reinforced Concrete Frame Buildings, Engineering Structures, 2016.

[31]Yaghmaei-Sabegh, Saman, and Jorge Ruiz-García. Nonlinear response analysis of SDOF systems subjected to doublet earthquake ground motions: A case study on 2012 Varzaghan-Ahar events. Engineering Structures, 2016, 110: 281-292.

[32] Nazari, N., van de Lindt, J.W. and Li, Y. Quantifying Changes in Structural Design Needed to Account for Aftershock Hazard, Journal of Structural Engineering, ASCE 2016.

[33] Zhai, C.H.,W.P. Wen, Z.Q. Chen, S. Li, L.L. Xie Damage spectra for the mainshockaftershock sequence-type ground motions. Soil Dyn Earthq Eng, 2013, 45; 1-12..

[34] Li, Y., Song, R., and van de Lindt, J.W. Collapse Fragility of Steel Structures Subjected to Earthquake Mainshock-Aftershock Sequences, Journal of Structural Engineering, ASCE, 2015. 140(12), 04014095.

[35]. Han, R., Li, Y. and van de Lindt, J.W. Seismic Risk of Base Isolated Non-ductile Reinforced Concrete Buildings Considering Uncertainties and Mainshock-Aftershock Sequences, Structural Safety, 2014. 50, 39-56.

[36] Lignos DG, Krawinkler H. Sidesway Collapse of Deteriorating Structural Systems Under Seismic Excitations. Stanford University; 2009.

[37] Lignos DG, Krawinkler H, Whittaker AS. Prediction and validation of sidesway collapse of two scale models of a 4-story steel moment frame. Earthquake Eng Struc. 2011;40:807-25.

[38] Field E. Probabilistic seismic hazard analysis (PSHA): A primer. Web site: http://www. relm. org/tutorial_materials/PSHA_Primer_v2.pdf; 2005.

[39] ICC. 2003 International Building Code. Falls Church (VA): International Code Council; 2003.

[40] ASCE-7. Minimum design loads for buildings and other structures. Reston (VA): Structural Engineering Institute (SEI). 2002.

[41] AISC. Seismic Provisions for Structural Steel Buildings, Including Supplement No. 1. Chicago (IL): American Institute of Steel Construction (AISC); 2005.

[42] OpenSees. The Open System for Earthquake Engineering Simulation. Available from: http://opensees.berkeley.edu: Pacific Earthquake Engineering Research Center (PEER); 2012.

[43] Eads L, Miranda E, Krawinkler H, Lignos DG. An efficient method for estimating the collapse risk of structures in seismic regions. Earthquake Eng Struc. 2013;42:25-41. 
[44] Lignos DG, Krawinkler H. Deterioration Modeling of Steel Components in Support of Collapse Prediction of Steel Moment Frames under Earthquake Loading. J Struct Eng. 2011;137:1291-302.

[45] Ibarra LF, Medina RA, Krawinkler H. Hysteretic models that incorporate strength and stiffness deterioration. Earthquake Eng Struc. 2005;34:1489-511.

[46] ATC-63. Quantification of building seismic performance factors. Redwood City (CA): FEMA P695; 2009.

[47] Abrahamson N, Silva W. Summary of the Abrahamson \& Silva NGA Ground-Motion Relations. Earthquake Spectra. 2008;24:67-97.

[48] Reasenberg PA, Jones LM. Earthquake hazard after a mainshock in California. Science. 1989;243:1173-6.

[49] Reasenberg P, Jones L. Earthquake aftershocks: update. Science. 1994;265:1251-2.

[50] Yeo GL, Cornell CA. Post-quake decision analysis using dynamic programming.

Earthquake Eng Struc. 2009;38:79-93.

[51] Gutenberg B, Richter CF. Seismicity of the earth and associated phenomena. Princeton (NJ): Princeton University Press; 1949.

[52] Ömori F. On the after-shocks of earthquakes: The University; 1894.

[53] Utsu T, Ogata Y. The centenary of the Omori formula for a decay law of aftershock activity. J Phys Earth. 1995;43:1-33.

[54] Sunasaka Y, Kiremidjian AS. A method for structural safety evaluation under mainshockaftershock earthquake sequences: The John A. Blume Earthquake Engineering Center; 1993. [55] Li Q, Ellingwood BR. Performance evaluation and damage assessment of steel frame buildings under main shock-aftershock earthquake sequences. Earthquake Eng Struc. 2007;36:405-27.

[56] Bratley P, Fox BL, Schrage LE. A guide to simulation. New York: Springer-Verlag; 1987. [57] Burnecki K, Härdle W, Weron R. An Introduction to Simulation of Risk Processes. Wroclaw (Poland): Wroclaw University of Technology; 2004.

[58]. Strasser, F.O., Bommer, J.J. and Abrahamson, N.A. Estimating ground-motion variability: issues, insights \& challenges, The 14th World Conference on Earthquake Engineering, Beijing, China, 2008.

[59] Li Y, Ellingwood BR. Reliability of woodframe residential construction subjected to earthquakes. Struct Saf. 2007;29:294-307.

[60] Luco N, Cornell CA. Effects of random connection fractures on the demands and reliability for a 3-story pre-northridge SMRF structure. 6th US National Conference on Earthquake Engineering. Seattle, Washington1998.

[61] Cornell CA, Jalayer F, Hamburger RO, DA F. Probabilistic basis for the 2000 SAC federal emergency management agency steel moment frame guidelines. J Struct Eng. 2002;128:526-33. [62] SAC. Suites of earthquake ground motions for analysis of steel moment frame structures. Available from: http://nisee.berkeley.edu/data/strong_motion/sacsteel/ground_motions.html: The SAC Steel Project; 2000.

[63] Vamvatsikos D, Cornell CA. Incremental dynamic analysis. Earthquake Eng Struc. 2002;31:491-514.

[64] Zareian F, Krawinkler H. Assessment of probability of collapse and design for collapse safety. Earthquake Eng Struc. 2007;36:1901-14. 
[65] REED. Construction Cost Estimates for Office (2-4 Story) in Los Angeles, California. Available from: http://www.reedconstructiondata.com/rsmeans/models/offices2/california/losangeles/: Reed Construction Data; 2008.

[66] McKay MD, Beckman RJ, Conover WJ. A Comparison of Three Methods for Selecting Values of Input Variables in the Analysis of Output from a Computer Code. Technometrics. 1979;21:239-45.

[67] Vamvatsikos D, Fragiadakis M. Incremental dynamic analysis for estimating seismic performance sensitivity and uncertainty. Earthquake Eng Struc. 2009:n/a-n/a.

[68] Yin Y-J, Li Y. Seismic collapse risk of light-frame wood construction considering aleatoric and epistemic uncertainties. Struct Saf. 2010;32:250-61.

[69] Iman RL, Helton JC, Campbell JE. An approach to sensitivity analysis of computer models, Part I- Introduction, input variable selection and preliminary variable assessment. J Qual Technol. 1981;13:174-83.

[70] Iman RL, Helton JC, Campbell JE. An approach to sensitivity analysis of computer models part II - ranking of input variables, response surface validation, distribution effect and technique synopsis. J Qual Technol. 1981;13:232-40. 